CIRJE-F-834

\title{
Empirical Analysis of the National Treatment Obligation Under the WTO: The Case of Japanese Shochu
}

\author{
Naoshi Doi \\ Graduate School of Economics, University of Tokyo \\ Hiroshi Ohashi \\ University of Tokyo \\ January 2012
}

CIRJE Discussion Papers can be downloaded without charge from:

http://www.cirje.e.u-tokyo.ac.jp/research/03research02dp.html

Discussion Papers are a series of manuscripts in their draft form. They are not intended for circulation or distribution except as indicated by the author. For that reason Discussion Papers may not be reproduced or distributed without the written consent of the author. 


\title{
Empirical Analysis of the National Treatment Obligation Under the WTO: The Case of Japanese Shochu*
}

\author{
Naoshi Doi ${ }^{\dagger} \quad$ Hiroshi Ohashi ${ }^{\ddagger}$
}

January 2012

\begin{abstract}
The national treatment obligation, along with the most favored nation obligation, is an important principle of non-discrimination adopted by the World Trade Organization. It requires that foreign products be treated no less favorably than national products. This paper empirically examines the 1996 WTO recommendation that a Japanese distilled alcoholic beverage, shochu, be classed as a "directly competitive or substitutable product" with regard to other distilled drinks, and thus that not taxing similarly be in violation of its national treatment obligation. Demand estimates obtained from a random-coefficient discrete-choice model reveal that a substitution pattern of shochu is far more complicated than that presumed by the WTO. Upon the WTO recommendation, Japan made all distilled alcoholic beverages be taxable at the same level in 2000. Our simulation analysis indicates that the revised tax rates improved but did not maximize Japanese national welfare.

Keywords: National treatment obligation; WTO; Random coefficient discrete choice model; tax.

JEL classification: F13; L66; H21
\end{abstract}

\section{Introduction}

The national treatment (NT) obligation, along with the most favored nation (MFN) obligation, is an important pillar supporting the principle of non-discrimination at the World Trade Organization (WTO). Whereas the MFN obligation requires equal treatment for goods from different nations,

\footnotetext{
${ }^{*}$ We are grateful to Hiroshi Mukunoki and seminar and conference participants at the JEA, Keio University and the RIETI for their helpful comments. We would also like to thank Kazutaka Takechi and Kentaro Nakajima for their earlier collaboration.

${ }^{\dagger}$ Graduate School of Economics, University of Tokyo

${ }^{\ddagger}$ Faculty of Economics, University of Tokyo. 7-3-1 Hongo Bunkyo Tokyo, 113-0033, Japan. Email: ohashi@e.utokyo.ac.jp
} 
the NT obligation requires the treatment of imported goods, once they have cleared customs, to be no worse than that of domestically produced goods (See for example Jackson, 1997). The NT obligation was adopted as part of the undertaking by the WTO to prevent domestic tax and regulatory policies from being used as protectionist tools that would offset its efforts to reduce border restrictions to the flow of goods. The interpretation of the NT obligation is of critical importance to WTO members, because it has a profound impact on these countries' freedom to formulate domestic policy.

A major interpretative issue with regard to the NT obligation is to determine whether imported and domestic products are "directly competitive or substitutable," under the stipulation of Article III.2 of the General Agreement on Tariffs and Trade (GATT) of 1994. While the absence of a "directly competitive and substitutable" relationship between imported and domestically produced products precludes any possibility of protectionist measures contrary to the NT provision, it is interesting to note that case law has not clarified the interpretation of the terms. As Horn and Mavroidis (2004: 43) state, the WTO has no clear methodology to offer for the interpretation of the NT obligation, let alone for determining which products might be "directly competitive and substitutable". To our knowledge, the present paper is the first to offer empirical evidence on the role of the NT obligation in regulation and taxation of Japanese alcoholic beverages.

In 1995, the EU, the US, and Canada requested consultations with Japan at the WTO, under the claim that a Japanese law taxed the locally produced alcoholic beverage shochu more favorably than several other import-dominated distilled alcoholic beverages (Japan-Tax on Alcoholic Beverages (WTO, 1996b), hereafter Japan-Tax). In November 1996, Japan accepted the WTO Appellate Body's recommendation that the complainants' claim be considered legitimate. To comply with the recommendation, Japan revised its Liquor Tax Law in 2000. An integral issue in this dispute was whether shochu and other distilled beverages were "directly competitive and substitutable" (DCS). ${ }^{1}$ In the dispute settlement process, the Appellate Body found that the decisive criterion in the determination of DCS is whether two products have common end-uses (inter alia) as shown by the elasticity of substitution (WTO, 1996b: 25). This empirical issue addressed by the WTO is highly relevant for the concept of market definition often employed in the fields of industrial organization and antitrust economics. Nevertheless, to our knowledge, the economics literature has devoted hardly any attention to this issue. Using the existing methods available in these fields, this paper revisits the Japan-Tax dispute, and evaluates ex-post whether the conclusion reached by the Panel makes sense - in other words, whether shochu and the other distilled beverages were in a DCS relationship with one another.

\footnotetext{
${ }^{1}$ The other issue in Japan-Tax was whether shochu and vodka are 'like' product. While the issue of likeness could be discussed in the realm of economics, the Appellate Body decided to rely not on economics but on customs classification (WTO, 1996b). We therefore take no further look into the issue on likeness in this paper.
} 
First, we perform the test of small but significant and non-transitory increase in price (SSNIP) to determine whether shochu and other distilled beverages constitute a relevant market. The SSNIP test is a convenient method used by antitrust practitioners to identify the smallest market relevant to product competition. Our test reveals that, contrary to the WTO recommendation, shochu by itself forms a relevant market, independent of other beverages. Since the SSNIP test is known to be vulnerable to possible statistical biases arising from endogeneity and omitted variables, we proceed to estimate Japanese consumer demand for alcoholic beverages to examine the robustness of the result obtained in the SSNIP test. We estimate a random-coefficient discrete-choice model by using the method recently proposed by Dubé, Fox, and Su (2011). Controlling for possible endogeneity in price, a substitution pattern is found to be far more complicated than that inferred from the SSNIP test: the cross-price elasticities are asymmetric and statistically different from zero.

The NT obligation is often deemed to be in conflict with national sovereignty. In Japan-Tax, the NT obligation placed severe constraints on the Japanese government's ability to freely determine domestic alcohol tax rates. In response to the WTO recommendation, the government increased tax rates on both shochu and liqueurs and decreased them on whisky and other spirits. Nearly four years after compliance with the recommendation, the Japanese government imposed the same tax rates on all distilled alcoholic beverages sold domestically. In this paper we perform simulation exercises based on the obtained demand estimates to assess this revision to Japanese liquor taxes from a welfare viewpoint, and find that, while the tax revision did improve domestic welfare, the ideal tax structure derived from our analysis implies that taxes on shochu should not have been raised, where in fact they nearly doubled.

The NT obligation has received notable academic attention recently. Horn (2006) offers the first formal analysis of the role of NT in bilateral trade agreements. He investigates the contractual incompleteness inherent in trade agreements over internal measures and shows that if tariff agreements account for subsequent tax setting, the NT obligation can improve government welfare even when a first-best contract would call for discrimination against imported products. Though the present paper does not share the analytical framework proposed by Horn (2006) and later extended by Saggi and Sara (2008), it finds empirical evidence consistent with their claim that the NT obligation enhanced but did not maximize Japanese national welfare.

The rest of this paper is organized as follows. The next section (Section 2) provides an overview of Japan-Tax. A major issue in the dispute was whether shochu was DCS to other distilled alcoholic beverages; to determine this, in this section, we define the Japanese distilled-beverage market using the SSNIP test often used in antitrust economics. To check the robustness of the findings of the test, in Section 3 we estimate a random-coefficient discrete-choice model of Japanese demand for alcoholic beverages in general. Using the estimation results, Section 4 assesses the extent to which 
the revised tax rates after the WTO recommendation had an impact on Japanese economic welfare. Section 5 provides some concluding remarks.

\section{Historical Background and Preliminary Analysis}

This section provides an overview of Japan-Tax, beginning with Subsection 2.1, which describes an overview of the WTO shochu dispute. A major issue in this dispute was whether shochu and other distilled beverages were "directly competitive and substitutable" (DCS) with each other. If they were, the complainant parties claimed, the wide gap between shochu taxes and other Japanese liquor taxes should have been unacceptable. While the WTO Appellate Body concluded that shochu and the other distilled alcoholic beverages were DCS, and that the variable taxes violated the WTO rule. However, the Body did not employ any precise criteria for the determination of DCS. In Subsection 2.2, we suggest a simple approach corresponding closely to the procedure taken by an antitrust authority, assessing the impact of, say, a proposed merger between companies. Our analysis concludes that shochu constituted a relevant market on its own, implying that it and other beverages were not in a DCS relationship. To check the robustness of the result obtained in Subsection 2.2, we perform a full-fledged demand analysis in the subsequent section, 2.3.

\subsection{Overview of the WTO Dispute}

On June 21, 1995, the EU requested consultations with Japan concerning the internal taxes levied by the Japanese government on certain alcoholic beverages pursuant to Japan's Liquor Tax Law (WTO, 1995a). In the following month, the US (WTO, 1995b) and Canada (WTO, 1995c) joined the consultations. These three parties made essentially the same complaint: that Japan had acted inconsistently with Article III of GATT by applying higher tax rates to distilled alcoholic beverages, with the exception of Japanese shochu.

At the time of the consultations, Japan's Liquor Tax Law classified alcoholic beverages into seven categories, four of which were classed as distilled alcohol and as a result come under the direct focus of this study; these are shochu, liqueur, spirits, and whisky (considered as a category of its own). The other three were brewed alcohol, including beer and cider; wine; and sake. ${ }^{2}$ The liquor tax on distilled beverage was imposed according to quantity: in 1995, the tax rates, adjusted by alcohol content, ranged from JPY 5,280/10 L on shochu to JPY 24,558 on whisky, as shown in Figure 1. ${ }^{3}$ While the law made no explicit distinction between domestic and imported alcoholic

\footnotetext{
${ }^{2}$ The category of sake includes sake compounds and mirin vinegar.

${ }^{3}$ To be precise, two kinds of shochu are sold in Japan, depending on the degree of alcohol content. Shochu group A contains 36 percent alcohol or lower, and shochu group B has a higher alcohol content. Because of the limited availability of price data, we use the sales-weighted average of the two groups in this study.
} 
beverages, the complainant parties said that Japan unduly favored (domestic) shochu over other distilled beverages, the latter of which were disproportionately imported. Indeed import share of shochu accounted for a mere 3.4 percent of domestic consumption in 1994, whereas whisky and other spirits accounted for 22.5 and 27.5 percents respectively.

The complainants and Japan submitted quantitative evidence to a WTO Dispute Panel. The Japanese government cited statistics on the correlation between price and consumption trends for the previous twenty years. In contrast, the complainants based their argument on the reactions of a sample of 400 shochu drinkers to a series of different combinations of price levels for shochu and spirits. While this evidence appears to be subject to either endogeneity in price or bias in sampling procedure, the Panel nevertheless ruled in favor of the complainants. The WTO Appellate Body subsequently concluded, in the final report on the matter in 1996, that shochu and the other distilled beverages were in a DCS relationship, and that Japan, by not taxing them at similar levels, was in violation of its obligation under Article III:2, second sentence, of the GATT (WTO, 1996b: 32). In response to the judgment of the Appellate Body, the Japanese government passed a new amendment to the Liquor Tax Law in October 2000, taxing shochu at the same rate as other distilled beverages, as shown in Figure 1.

During the settlement process, neither the WTO Panel nor the Appellate Body offered precise criteria as to how DCS should be determined. While the Appellate Body listed in its report factors relevant to the criteria, such as cross-price elasticity, product characteristics, and consumer tastes and habits, it also noted that its list was not exhaustive, and thus did not clarify what weight was to be given to each of the factors mentioned.

If we understand that the concept of DCS is intended to capture the degree to which an increase in the tax on a set of products benefits another set of products in terms of increased sales volume, the appropriate indicator for DCS must then be cross-price elasticity. In the subsequent sections of this paper, we present formal statistical methods to measure the degree of DCS between shochu and other distilled beverages in Japan-Tax. We utilize publicly available data and attempt to address the econometric issues that emerge from this empirical application, which were not adequately handled in Japan-Tax. We believe that the statistical method proposed in the following sections will help us understand how to determine DCS, as stipulated in the NT obligation.

In section 3, we apply a discrete choice model to directly estimate cross-price elasticity and assess the validity of the claim in that shochu and other distilled beverages are DCS toward each other. First, however, Subsection 2.2 presents a much simpler technique to assess DCS between shochu and other alcoholic beverages. 


\subsection{Preliminary Analysis of Market Definition}

In evaluating the DCS relationship between multiple products, an adjudicating body essentially asks whether the products are in the same relevant market (i.e., whether the level at which the products are in the same market is the relevant level). If the products are determined to be in the same market, they must be highly substitutable for each other in the eyes of consumers. Otherwise, they are not deemed to be in direct competition. While the WTO has no clear approaches to defining the relevant market, it is noted in the report that "Under national antitrust [...] regimes, the extent to which products directly compete is measured by the elasticity of substitution" (Paragraph 6.31 of WTO, 1996a).

Before we estimate cross-price elasticity (in Section 3), this subsection proposes the SSNIP test to identify the smallest market relevant to the product competition of the products under consideration. The method finds (to anticipate the result) that shochu constitutes an independent market of its own, and thus is not DCS to spirits. After presenting the results, we point out the weaknesses of the test, which lead us to use another method to assess Japanese demand for alcoholic beverages, as will be seen in the next section.

The SSNIP test was introduced with the US Merger Guidelines of 1982 and has been widely used by competition authorities to define relevant markets, in a variety of contexts. Starting with the narrowest possible market definition, if it is profitable for a hypothetical monopolist to increase the price(s) of product(s) in this candidate market by 5 percent, the candidate market is determined to be the relevant market. This is because the presence of a hypothetical profitable monopolist implies that the elasticity of substitution of products outside the candidate market is small. If, on the other hand, the increase in price is not profitable because consumers would substitute products outside the candidate market, the market definition must be extended to include the closest of these substitutes in order to ensure that any product exercising a competitive pressure on the product(s) in question is included in the market definition. Products are added to the candidate market until a 5 percent price increase is profitable for a hypothetical monopolist owning all the products in the candidate market. The relevant market has then been found.

As Katz and Shapiro (2003) concisely explain, the effect of an SSNIP on a hypothetical monopolist's profit depends on the percentage of unit sales that would be lost as a result of a 5 percent price increase as well as on the prevailing profit margin earned on each unit sold. The price increase will be profitable, if the following inequality holds:

$$
\frac{\Delta q_{j, t} / q_{j, t}}{\Delta p_{j, t} / p_{j, t}}>-\frac{1}{\left(\Delta p_{j, t} / p_{j, t}\right)+M U_{j, t}}
$$

where $q_{j, t}, p_{j, t}$ and $M U_{j, t}$ are respectively quantity demanded, price and markup for product $j$ in 
year $t$; and $\Delta h_{j, t}$ is defined as $h_{j, t}-h_{j, t-1}$, where $h$ is either $p$ or $q$. We are interested in investigating whether or not shochu is DCS to other alcoholic beverages - in other words, whether Japanese shochu data satisfy equation (1).

Figure 2 shows quantity and price data for the distilled alcoholic beverages examined in this study. The data, which are publicly available, are traced back to the year of 1994 and forward to 2001, when the revision of the Liquor Tax Law had been completed. The aggregated national-level data indicate that equation (1) always holds for any values of $M U_{j, t}$ : the left-hand side of (1) takes the value of 11.24, whereas the right-hand side always takes a negative value. This observation would suggest that shochu constitutes a relevant market on its own, independent of other distilled beverages. This inference depends crucially on the observation made in Figure 2, in that price and quantity of shochu appear to move in the same direction: indeed, the unconditional correlation coefficient is 0.26 . As noted by Trajtenberg (1990), this positive correlation may be due to the lack of control for endogeneity in the price variable. In the next section, we address these econometric issues in the demand estimation.

\section{Demand Model of Alcoholic Beverages}

This section describes the estimation model we use to explain the Japanese alcoholic beverage market. In Subsection 3.1, we introduce a demand system derived from a random-utility discretechoice model of consumer behavior. We do not observe individual purchasing behavior, but instead, aggregate across individual buyers to obtain the demand for an alcoholic product while still allowing for heterogeneity across consumers. Subsection 3.2 addresses identification issues of this model, and Subsection 3.3 discusses the estimation results. The demand model and its estimates provide a basis for the analyses in Section 4, in which we assess the extent to which the revised tax rates following the WTO recommendation have affected economic welfare in Japan.

\subsection{Discrete-Choice Model}

This subsection describes a random-coefficient discrete choice model of alcoholic beverages in Japan. In any particular year, we take an individual of legal drinking age as the purchasing entity, where each individual has a unit demand for a bottle of alcoholic beverage on a daily basis. We denote the market size by $M S .{ }^{4}$ Our lack of data on individual purchases does not allow us to distinguish between the decision to visit a store and the decision of how many of bottles to purchase. Since a bottle size varies, we standardize it at $750 \mathrm{~mL} .^{5}$ Each individual $i$ who is part of market $m$

\footnotetext{
${ }^{4}$ The legal drinking age in Japan is twenty years old. We tested an alternative measure of market size to assess the population above 15 years old. The demand estimates reported in Section 3.3 are robust to the alternative definition.

${ }^{5}$ The alternative assumptions of either $500 \mathrm{~mL}$ or $1 \mathrm{~L}$ for the bottle size make no qualitative difference to the results.
} 
$(=1, \ldots, M)$ is assumed to maximize the following indirect utility function at time $t(=1, \ldots, T)$ by choosing alcoholic beverage $j$ among $J_{t}+1$ alternatives, one of which is the option of not purchasing alcoholic beverages: ${ }^{6}$

$$
u_{i, j, m, t}=\beta_{0}+\frac{\alpha}{y_{i, m, t}} p_{j, m, t}+\mathbf{x}_{j, m, t}^{\prime} \boldsymbol{\beta}_{i, m, t}+\xi_{j, m, t}+\epsilon_{i, j, m, t}
$$

where $u_{i, j, m, t}$ is consumer $i$ 's utility from consuming the alcoholic beverage $j$ in market $m$ at time $t$. The income for consumer $i$ who purchases in market $m$ at time $t$ is denoted by $y_{i, m, t}$, and the price of a bottle of alcoholic beverage $j$ is denoted by $p_{j, m, t}$. Both variables are deflated by the overall CPI index to constant 2005 yen. Note that $p_{j, m, t}$ is after tax; we will discuss in Section 4 how liquor taxes effect the price. The annual data have a regional dimension - we view each of Japan's 47 prefectures to be an independent market in this paper. The vector $\mathbf{x}_{j, m, t}$ denotes alcoholic beverage $j$ 's observed attributes, whose $k$-th component is denoted by $x_{j, k, m, t}$. We use in this vector the variables of normalized alcoholic content and a dummy variable that takes one if beverage $j$ is distilled and zero otherwise. Our data set contains both brewed and distilled alcoholic beverages, the former including beer (5), sake (15) and wine (13), and the latter liqueurs (12), shochu (25), spirits other than whisky (37) and whisky (40). Inside the parenthesis is the drink's alcohol content (as percentage). The term $\alpha$ denotes consumer's sensitivity to changes in real price and income, the parameter to be estimated. The utility function contains $\xi_{j, m, t}$, an unobserved (to an econometrician) product quality of alcoholic beverage $j$ with the property that $E\left(\xi_{j, m, t}\right)=0$. In Subsection 3.2, we discuss an econometric endogeneity problem generated by $\xi_{j, m, t}$.

To enable richer substitution patterns, we follow the model of Berry, Levinsohn and Pakes (1999), allowing different consumers to have different intensities of preferences for different beverage characteristics, $\mathbf{x}_{j, m, t}$. We rely on a random-coefficient utility specification and assume that individual preference intensity is represented by $\boldsymbol{\beta}_{i, m, t}$, whose $k$-th component is denoted by $\beta_{i, k, m, t}$ :

$$
\beta_{i, k, m, t}=\beta_{k}+\pi_{k} y_{i, m, t}+\nu_{i, k}
$$

where $\nu_{i, k}$ follows the normal distribution with mean zero and variance $\sigma_{k}$. Note that for each characteristic of $x_{j, k, m, t}$, consumer $i$ 's taste varies with her income $y_{i, m, t}$ and a taste shock $\nu_{i, k}$. While we lack data on individual consumer income, the income distribution at the market level is well approximated by the log-normal distribution, $d G_{m, t}(y)$, with the mean and variance of the distribution being obtained annually from Shinozaki (2007). Note that $y_{i, m, t}$ is the $(i, m, t)$ th component of $y$, and that the density $d G_{m, t}(\cdot)$ is allowed to differ by year and market. We

\footnotetext{
${ }^{6}$ The market share for the outside option is on average 65 percent. In the study period, no entry nor exit of products is observed; thus $J_{t}$ does not depend on $t$.
} 
assume that the taste variable, $\nu_{i, k}$, is drawn from an i.i.d. standard normal distribution, and the parameters to be estimated, $\pi_{k}$ and $\sigma_{k}$, capture the variances in consumer tastes for characteristic $x_{j, k, m, t}$. Consumers with similar demographic attributes tend to have similar product rankings, and thus similar substitution patterns. The inclusion of the random coefficients, $\boldsymbol{\beta}_{i, m, t}$ in (2) allows for correlation between alcoholic beverage types with similar characteristics, and thus presumably for more realistic substitution patterns relative to the traditional logit model.

Let $\epsilon_{i, j, m, t}$ represent the idiosyncratic taste of consumer $i$ for product $j$ in market $m$ at time $t$, and follows the type-I extreme value. We assume that the mean utility from the outside option is normalized to zero. The distribution assumption yields the following closed-form probability of consumer $i$ 's choosing product $j$ :

$$
s_{i, j, m, t}=\frac{\exp \left(\beta_{0}+\frac{\alpha}{y_{i, m, t}} p_{j, m, t}+\mathbf{x}_{j, m, t}^{\prime} \boldsymbol{\beta}_{i, m, t}+\xi_{j, m, t}\right)}{1+\sum_{l} \exp \left(\beta_{0}+\frac{\alpha}{y_{i, m, t}} p_{l, m, t}+\mathbf{x}_{l, m, t}^{\prime} \boldsymbol{\beta}_{i, m, t}+\xi_{l, m, t}\right)} .
$$

The market share of alcoholic beverage $j$, denoted by $s_{j, m, t}$, is obtained by

$$
s_{j, m, t}=\int_{y} \int_{\nu} s_{i, j, m, t} d F(\nu) d G_{m, t}(y)
$$

where $d F(\nu)$ represents the joint standard normal density of taste shocks, $\nu$, the $(i, k)$-th element of which is $\nu_{i, k}$, as introduced in (2). Note that the market share of the outside option, $s_{0, m, t}$, is obtained by $1-\sum_{j} s_{j, m, t}$. We make the independence assumption in $d F(\nu)$ and $d G_{m, t}(y)$, and follow the estimation method detailed in Dubé, Fox and Su (2011) to form a generalized method of moment (GMM) estimator. The population moment condition is a product of $\xi_{j, m, t}$ and instrumental variables introduced in the next subsection. While Berry, Levinsohn and Pakes (1995; BLP) proposes to numerically compute the market shares by means of inversion, Dubé et al (2011) points out that the BLP method would generate numerical errors in calculating the nested fixed point. They instead propose to solve a mathematical program under the constraint that $s_{j, m, t}$ as obtained in (3) equals the observed market shares. ${ }^{7}$ In the next subsection, we discuss the instrumental variables used for the GMM objective function.

\subsection{Instruments}

We are concerned that the variable of price may be correlated with the error, $\xi_{j, m, t}$. It is likely that the observed characteristics do not capture all the important dimensions of the alcoholic beverages under study; indeed, $\xi_{j, m, t}$ is often interpreted as the unobserved quality error. If $\xi_{j, m, t}$ is correctly

\footnotetext{
${ }^{7}$ For each combination of $m$ and $t$, we draw 20 individuals for $y_{i, m, t}$ from the distribution $d G_{m, t}(y)$, and another 1,000 draws of $\nu_{i, k, m, t}$ from $d F(\nu)$ for those consumers who have income of $y_{i, m, t}$. Doubling the number of draws make little changes to the estimation results discussed in the next section.
} 
perceived by consumers and sellers in the market, this unobserved quality error is likely to be correlated with price: Better-quality products may induce higher willingness to pay, and sellers may be able to charge higher prices, perhaps due to higher marginal costs.

Traditionally, the cost variables excluded from $\mathbf{x}_{j, m, t}$ are used as instruments in homogeneousgoods models, and this practice is still appropriate here. As an instrument of this sort, we employ liquor tax per bottle, standardized by alcohol content. The liquor tax is levied on producers before the product is shipped; thus, the tax is included in the price measure, and it is unlikely to be influenced by unobserved demand shocks.

In a product differentiation model, the costs of rival products are appropriate instruments. With market power in supply, the markup of each product depends on the costs of the other products. The liquor taxes on the other products are thus related to $p_{j, m, t}$, but since the liquor tax is assumed to be exogenous, they are still valid instruments. We include in the set of instruments the sum of liquor taxes of other products in the distilled and brewed alcoholic beverages.

Information from the income distribution may also help identify the parameter, $\alpha$. We use as instruments the means and variances of the distribution by market and by year, from which we draw the sample of individuals in the estimation of (2). ${ }^{8}$ We also include in the set of instruments the interaction terms between the mean income levels and three exogenous variables, namely, alcohol content and liquor tax rate for each beverage and a dummy variable for distilled drinks.

\subsection{Demand Estimates}

This subsection presents estimation results for the demand model discussed in the previous subsection. The dataset of annual frequency used covers the 1994-1995 period, during which the WTO conducted their investigation for Japan-Tax. We define the geographic market $m$, as one prefecture. In the demand estimation, we include data on brewed as well as distilled beverages, so that a consumer in the model has eight choices, including the outside option. By incorporating brewed beverages in our analysis, we hope that our estimates of cross-price elasticities below will be insusceptible to the assumption of an outside option. We describe the data sources in the Appendix.

Table 1 presents three estimation results. Models (1-A) and (1-B) are based on a standard logit model, in which we allow for no heterogeneity in individual preferences. In these models, we replace the second term in the right-hand side of $(2)$ with $\alpha p_{j, m, t}$, and impose on the indirect utility (2) a restriction on the same coefficients across individuals (in other words, $\pi_{k}$ and $\sigma_{k}$ are zero). While (1-A) is estimated by the ordinary-least squares (OLS) method, (1-B) is not, and

\footnotetext{
${ }^{8}$ To check the robustness of the sampling procedure regarding income distribution, we further disaggregate $G_{m, t}(y)$ by gender and use the data on the ratio of male and female workers by market and by year to estimate the model. The qualitative results discussed in the rest of the paper do not change under this alternative specification.
} 
allows for endogeneity in the price coefficient. The first-stage $F$-statistic for the explanatory power of the instruments conditional upon the included exogenous variables is 124.6, indicating that the instruments are not weak. The estimated price coefficients are found positive.

Estimates obtained from the random-coefficient model discussed in Subsection 3.1 are shown under (1-C). The chi-squared statistic tests the validity of the instruments conditional on there being a set of valid instruments that just identify the model. This does not allow us to reject the orthogonality condition between some of the instruments and the error term.

The random-coefficient model appears to fit the data moderately well. We calculate the goodness of fit measure, which summarizes the discrepancy between observed market shares and the shares predicted under the model in question. The goodness of fit is 0.84 for (1-C) and 0.19 for (1-B). This finding corroborates with the estimated correlation coefficient between observed and predicted market shares, which is 0.96 for (1-C) and 0.62 for (1-B).

We also examine out-of-sample predictions for the five years (1996-2001) after the period of estimation. Surprisingly, given the substantial changes in liquor tax rates over the period shown in Figure 1, Model (1-C) explains the data well over this 5-year period, with a goodness of fit measure of 0.54 , and does especially well in predicting market shares: the correlation coefficient between observed and predicted market shares is 0.94. This out-of-sample analysis provides additional evidence on the importance of incorporating preference heterogeneity when accounting for the data under study.

The mean of the coefficient in the alcohol content variable is estimated to be negative and statistically significant. The estimated standard deviation of the same coefficient implies that consumer preference regarding alcohol content is indeed diverse. The estimates also indicate that consumers with higher income tends to prefer beverages with lower alcohol content. However, none of the coefficients in the distillation dummy variable are statistically significant. This finding may indicate that the average consumer is indifferent to whether the alcoholic beverage in question is distilled or brewed. This observation has a bearing on the substitution pattern discussed below in this section.

The price coefficient is negative and statistically different from zero. Using the obtained price estimate from Model (1-C), we present in Table 2 estimated own- and cross-price elasticities for all the seven types of beverage under study. The $(m, n)$ element in the elasticities matrix indicates the elasticity of $n$ with respect to a change in the price of $m$. While the logit model restricts all elasticities in a particular row of the matrix to the same value, a random-coefficient model allows these elasticities to differ with differences in the price sensitivity between different types of consumers purchasing various alcoholic beverages. The table indicates that the demand for distilled beverages is inelastic, lying in the range from -0.50 for whisky to -0.10 for shochu. A closer look at 
the table shows also that demand for beer, the value of which is -0.09 , is less elastic than demand for the distilled beverages. These findings are similar to those found in previous literature. Fogarty (2010), for example, reviews actual, reported individual-country own-price elasticity estimates, concluding that the demand for alcoholic beverages is price-inelastic and finds little support for the idea that demand for alcoholic beverages (except wine) varies fundamentally across most countries. Cook and Moore (1999), and Chaloupka, Grossman, and Saffer (2002) also report that the demand for beer is the least elastic among these alcoholic beverages, which corroborates with our estimates presented in Table 2 .

Cross-price elasticities among distilled beverages are statistically different from zero, but appear to be economically insignificant. The estimated random coefficient for alcohol content indicate that individual consumers had different tastes regarding the amount of alcohol in their drinks. Indeed, Table 2 shows that, although the values are small, cross-price demand for beverages with similar alcohol content is more elastic than for beverages with widely divergent alcohol content. While market-level aggregated data do not allow us to infer the underlying reasons for these small crossprice elasticities, they may be due to persistent consumer habits regarding the purchase of alcoholic beverages. Indeed, Fogarty (2010) reports that consumers respond to price discounting by engaging in inventory behavior rather than substituting different alcoholic beverages.

The estimated substitution pattern, being statistical significant but economically insignificant, seems to fall between the claims of the complainants in Japan-Tax and those of Japan; the former argued that all distilled beverages were DCS, while the latter alleged that shochu was not DCS with the other distilled alcohol beverages. The Panel and the Appellate Body agreed with the complainants, and as a result, the Japanese government revised its Liquor Tax Law to tax all distilled beverages at the same rates. We evaluate this revision in the next section.

\section{Evaluating Japan's Liquor Taxes}

The NT obligation is often seen as imposing constraints on national sovereignty (Jackson, 1997). With regard to the Japanese Liquor Tax Law under study, the NT obligation constrained the Japanese government from freely determining domestic alcoholic taxes; in conformity with the WTO's recommendation, the government eventually reformed the Law in 2000 to tax all distilled alcoholic beverages at the same rate. As shown in Figure 1, the revised tax rates on whisky were more than 50 percent lower than the previous rates, and those on shochu and liqueurs increased respectively by 93 and 21 percents.

Did this tax revision contribute to the national welfare? This section provides an answer to the question. Based on the model and estimates reported in the previous sections, this section measures the impact of the tax revision on Japanese people's economic welfare. Below, we begin 
with a definition of "social surplus" based on the demand model presented in Subsection 3.1 and then evaluate the Japanese liquor tax revision completed in 2000.

It is reasonable to assume that the social welfare is the sum of three elements: consumer surplus, $C S_{t}$; producer surplus, $P S_{t}$; and tax revenues, $T R_{t}$. All three of them are a function of $r_{t}$, a vector of the liquor tax rates at the end of period $t$. Note that, as shown in Figure 1, liquor tax rates differ by beverage type but are uniform across markets. Given the finding in the previous section that brewed beverages are not often substituted for distilled ones, we focus solely on distilled beverages in this section. The consumer surplus, represented by the compensating variation, is written as follows:

$$
C S_{t}=\sum_{m} M S_{m, t} \int_{y} \int_{\nu} \frac{\ln \left(1+\sum_{l} V_{i, l, m, t}\right)}{-\frac{\alpha}{y_{i, m, t}}} d F(\nu) d G_{m, t}(y)
$$

where

$$
V_{i, j, t, m} \equiv \exp \left[\beta_{0}+\frac{\alpha}{y_{i, m, t}} p_{j, m, t}\left(r_{t}\right)+\mathbf{x}_{j, m, t}^{\prime} \boldsymbol{\beta}_{i, m, t}+\xi_{j, m, t}\right] .
$$

Remember that $M S_{m, t}$ is the market size at market $m$ in year $t$. The price of product $j$ is now a function of $r_{t}$, while the relationship between $p_{j, m, t}$ and $r_{t}$ depends on the degree of "passthrough", which is determined by market competitiveness and elasticity of demand. For example, if the market is perfectly competitive, the pass-through is complete; whereas if the elasticity of demand is perfectly elastic, the pass-through is nil.

To obtain a sense of the degree of pass-through in our study, we assessed the supply-side behavior of the Japanese liquor market. With a lack of data on individual suppliers, we have no knowledge of either their production costs or their ownership structure. Under the assumption that each supplier sells one type of product $j$, a solution to the profit maximization problem for product $j(=1, \ldots, J)$ is given by:

$$
\left(\begin{array}{c}
p_{1} \\
: \\
p_{J}
\end{array}\right)=\left(\begin{array}{c}
m c_{1} \\
: \\
m c_{J}
\end{array}\right)-\Theta \cdot\left(\begin{array}{cccc}
\frac{\partial s_{1}}{\partial p_{1}} & \frac{\partial s_{2}}{\partial p_{1}} & \ldots & \frac{\partial s_{J}}{\partial p_{1}} \\
\frac{\partial s_{1}}{\partial p_{2}} & \frac{\partial s_{2}}{\partial p_{2}} & \ldots & : \\
: & : & \ldots & : \\
: & : & \ldots & \frac{\partial s_{J}}{\partial p_{J}}
\end{array}\right)^{-1} \cdot\left(\begin{array}{c}
s_{1} \\
: \\
s_{J}
\end{array}\right)
$$

or

$$
p=m c-\Theta \cdot B(p) \cdot s
$$

where $p \equiv\left(p_{1}, \ldots, p_{J}\right)^{\prime}, s \equiv\left(s_{1}, \ldots, s_{J}\right)^{\prime}$, and $m c \equiv\left(m c_{1}, \ldots, m c_{J}\right)^{\prime}$. Note that $A_{j}$ is a vector of $\left(A_{j, 1,1}, \ldots, A_{j, M, T}\right)$, where $A$ is either $p, s$ or $m c$. Eq. (5) implies that price, $p$, consists of two 
elements: marginal cost, or $m c$, and markup, represented by the second term on the right-hand side of the equation. The latter element depends on the degree of competitiveness in the market of product $j$, denoted by a $(M \cdot T) \times 1$ vector, $\theta_{j}$. The diagonal matrix $\Theta$ is defined as $\operatorname{diag}\left(\theta_{1}, \ldots, \theta_{J}\right)$. Note that, conditional on product $j$, we assume that the value of $\theta_{j}$ is the same for all $m$ and $t$. Conduct parameter $\theta_{j}$ takes a value from 0 (where the market is perfectly competitive) to 1 (where the market is monopolistic). We estimate $\Theta$ below in this section. Note that $s_{j}$ is presented as a fraction of the total number of consumers who are of legal drinking age.

Each element of $B$ is calculated from the probability formula defined in (3). Note that the cross derivatives differ, depending on the consumer attributes $\nu$ and $y$. Each component of $B$ can be computed by the demand estimates. The marginal cost of producing beverage $j$ for market $m$ in year $t$ is denoted by $m c_{j, m, t}$. Since no data are available on product-level marginal cost, we substitute $m c$ with the matrix of year- and product-dummies, $D$, with a vector of parameters, $\gamma$, to be estimated. Thus, using the data and obtained demand estimates presented in Table 3, we estimate the following system of equations in the 1994-1995 data:

$$
p=D^{\prime} \gamma-\Theta \cdot \widehat{B} \cdot s+e
$$

Note that $\widehat{B}$ is the cross-derivative acquired using the demand estimates under Model (1-C), and $e$ is a vector of the error term. We apply 2SLS to the above equation by using as instruments the variables associated with the income distribution introduced in Subsection 3.2. As shown in Table 3, none of the conduct parameters, $\Theta$, are estimated to be statistically different from zero, implying that the market is reasonably approximated by a model assuming perfect competition. This result is robust to the inclusion of the market-specific dummy variable in $D$ (under 3 -B), or to the expansion of the product categories to incorporate brewed alcoholic beverages (under 3-C).

Combining this finding with the fact that many producers exist in each market, it may be reasonable to assume that the liquor tax on product $j$ has complete pass-through on $p_{j}$. The demand estimates obtained in Section 3 enable us to assess the extent to which the quantities demanded respond to the changes in $r_{t}$. The tax revenues, $T R_{t}$, are thus calculated as the product of $r_{t}$ and $\sum_{m} M_{m, t} \cdot\left(s_{1, m, t}, \ldots, s_{J, m, t}\right)^{\prime}$.

Table 4 shows consumer welfare and tax revenues before and after the tax revision. We employ the demand estimates under (1-C) in Table 1 to calculate consumer welfare before the revision using (4). The same procedure is applied to the calculation of the consumer surplus after the revision, except that we now employ the post-revision tax rates in 2000, $r_{2000}$, when the tax revision completed. The effect of the liquor tax revision on consumer surplus is therefore evaluated by the difference between surpluses before and after the revision. National welfare is the sum of consumer welfare and tax revenues under the competitive market inferred from the above exercise. 
Table 4 indicates that the increase in taxes on shochu and liqueurs had more effect on consumer surplus than the decrease in tax on whisky. This is mainly because, as seen in Table 3 and Figure 1, the demand for shochu is less elastic and the size of the demand four times larger than that for whisky. As a consequence, the consumer surplus would have declined as a result of the tax revision to comply with the WTO recommendation. On the other hand, the increase in shochu tax rates substantially improve Japanese government revenue. All in all, the liquor tax revision improved the social surplus by the annual amount of JPY 6.87 billion, or the equivalent of USD 62 million. ${ }^{9}$

In order to assess how close revision moved the liquor tax structure to optimal, we compute the optimal tax rates (those which maximize the social surplus as defined above in this section). The optimal tax rates for the year of 1995 are shown in Figure 3. In accordance with the measure used by the WTO and with the structure of the Liquor Tax Law in Japan, we transform the tax rate per bottle into the rate per $10 \mathrm{~L}$ on the assumption of 100 -percent alcohol content. It is worthwhile to observe that the optimal tax rates differ substantially across beverage types, reflecting mainly differences in the values of own-price elasticities. In particular, we find that optimal tax rates positively correlate with the alcohol content of the liquor. The optimal tax rates per bottle is estimated to be respectively JPY 97.4 for shochu (25 percent alcohol), 75.8 for liqueur (12 percent), 102.1 for spirits (37 percent) and 102.5 for whisky (40 percent).

It is also interesting to note that the tax rates on shochu and liqueurs were set close to the optimal level, whereas the tax on whisky seems to have been excessive. In implementing the WTO recommendation, the Japanese government thus appears to have partially corrected for prior distortion in the consumption of whisky but introduced new distortion in the consumption of shochu and liqueurs. This new distortion came into being primarily because the WTO recommended that the tax rates on all distilled beverages, including shochu, should be the same. This recommendation was presumably made on the basis of the Appellate Body's finding that shochu was in a DCS relationship with other distilled alcoholic beverages. The estimated demand elasticities in Table 2 imply that the substitution pattern of distilled beverages is far more complicated than that suggested by DCS. Our calculation indicate that should the rates be optimally set, the social surplus would be enhanced by the annual amount of JPY 1.55 billion, or the equivalent of USD 13.99 million USD.

The findings above is consistent with a theoretical observation first made by Horn (2006) and later extended by Saggi and Sara (2008). Horn (2006) offers the first formal theoretical analysis of the role of the NT obligation. He examines the contractual incompleteness inherent in bilateral trade agreements over internal (e.g., tax) measures, and shows that if tariff agreements account for subsequent tax setting incentives, the NT obligation can improve welfare even when it is socially

\footnotetext{
${ }^{9}$ We use the averaged 2005 exchange rate of JPY 110.8 to the USD.
} 
optimal to discriminate against imports. While our current empirical framework do not contain a feature of contractual incompleteness like the one embedded in Horn (2006), our quantitative findings mentioned above corroborate his theoretical implication in that the NT obligation enhanced, but did not maximize, Japan's national welfare.

\section{Conclusion}

While the NT obligation is a pillar supporting the WTO's non-discrimination principle, it has been neglected in the literature relative to the attention given the MFN obligation. This paper has provided the first empirical study on the role of the NT obligation, using the case of Japan-Tax, in which the Panel and Appellate Body were confronted with a Japanese law taxing the locally produced alcoholic beverage shochu more lightly than distilled drinks dominated by import brands. Though Japan argued that shochu was not in a DCS relationship with the distilled beverages, the Panel and Appellate Body found that all products concerned were DCS with all others.

This paper employed a random-coefficient discrete-choice model to assess purchasing behavior of alcoholic beverages by Japanese consumers and identified an asymmetric structure in the estimated cross-price elasticities. This finding runs counter to the WTO recommendation that shochu is in a DCS relationship to other distilled beverages, and thus needs to be taxed similarly to them. Indeed, contrary to the claim of the complainants in Japan-Tax that shochu was treated excessively favorably in the Japanese liquor tax regime, this paper has discovered that the tax rate on shochu was close to the level which would have maximized the domestic social surplus, whereas the tax on whisky was excessively high. The paper finds that, while the policy adopted as a result of the WTO recommendation was not the best one from the national-welfare point of view, it did eventually improve Japan's social surplus by substantially reducing the tax on whisky.

\section{Appendix: Data Sources}

Estimating this model requires data on quantity, price, and alcohol content by beverage type, which were obtained from the Japanese Annual Statistical Data on Liquor $\mathcal{G}$ Food Industries in the period from 1994 to 2001. The data are disaggregated by prefecture, and we consider each prefecture to be an independent market. Data on alcohol content of distilled and brewed beverages is available from the National Tax Agency's Annual Statistics Report. The estimation also uses data on income distribution obtained from the Basic Survey on Wage Structure. Information on distribution means is annually available for each market, broken down by gender, from the Ministry of Health, Labor and Welfare, and information on the variance of the distribution is reported in Shinozaki (2007). 


\section{References}

[1] Annual Statistical Data on Liquor $\& 3$ Food Industries, 1994-2001, Tokyo: Nikkan Keizai Tsushin Co., Ltd. (in Japanese)

[2] Berry, S., J. Levinsohn, and A. Pakes, 1995, "Automobile Prices in Market Equilibrium," Econometrica, 63(4): 841-890.

[3] Berry, S., J. Levinsohn, and A. Pakes, 1999, "Voluntary Export Restraints on Automobiles: Evaluating a Trade Policy," American Economic Review, 89(3): 400-430.

[4] Chaloupka, F. J., M. Grossman, and H. Saffer, 2002, "The Effects of Price on Alcohol Consumption and Alcohol-Related Problems," Alcohol Research and Health, 26(1): 22-34.

[5] Cook, P. J. and M. J. Moore, 1999, “Alcohol,” NBER Working Paper 6905.

[6] Dubé, J., J. T. Fox, and C. Su, 2011, "Improving the Numerical Performance of BLP Static and Dynamic Discrete Choice Random Coefficients Demand," Chicago Booth School of Business Research Paper 11-14.

[7] Fogarty, J., 2010, "The demand for beer, wine and spirits: A survey of the literature," Journal of Economic Surveys, 24(3): 428-478.

[8] Horn, H., 2006, "National Treatment in the GATT," American Economic Review, 96(1): 394404.

[9] Horn, H. and P. C. Mavroidis, 2004, "Still Hazy after All These Years: The Interpretation of National Treatment in the GATT/WTO Case-law on Tax Discrimination," European Journal of International Law, 15(1): 36-69.

[10] Jackson, J. K., 1997, The World Trading System, Second Edition, Cambridge: MIT Press.

[11] Katz, M. L. and C. Shapiro, 2003, "Critical Loss: Let's Tell the Whole Story," Antitrust Magazine, 17(2): 49-56.

[12] National Tax Agency Japan, 1994-2001, Annual Statistics Report, Tokyo.

[13] Saggi, K. and N. Sara., 2008, "National Treatment at the WTO: The Roles of Product and Country Heterogeneity," International Economic Review, 49(4): 1365-1394.

[14] Shinozaki, T., 2007, "Chiikikan Chingin Kakusa to Chiikinai Chingin Kozo," in Shugyo Kankyo to Rodo Shijo no Jizokuteki Kaizen ni Muketa Seisaku Kadai ni Kannsuru Chosa Kenkyu Hokokusyo, ed. Employment and Human Resources Development Organization of Japan, chapter 9: 219-277. (in Japanese) 
[15] Trajtenberg, M., 1990, Economic Analysis of Product Innovation - The Case of CT Scanners, Cambridge: Harvard University Press.

[16] World Trade Organization, 1995a, WT/DS8/1 of 29 June 1995.

[17] World Trade Organization, 1995b, WT/DS8/2 of 17 July 1995.

[18] World Trade Organization, 1995c, WT/DS8/3 of 17 July 1995.

[19] World Trade Organization, 1996a, WT/DS8, 10, 11/R of 11 July 1996.

[20] World Trade Organization, 1996b, WT/DS8, 10, 11/AB/R of 4 October 1996. 


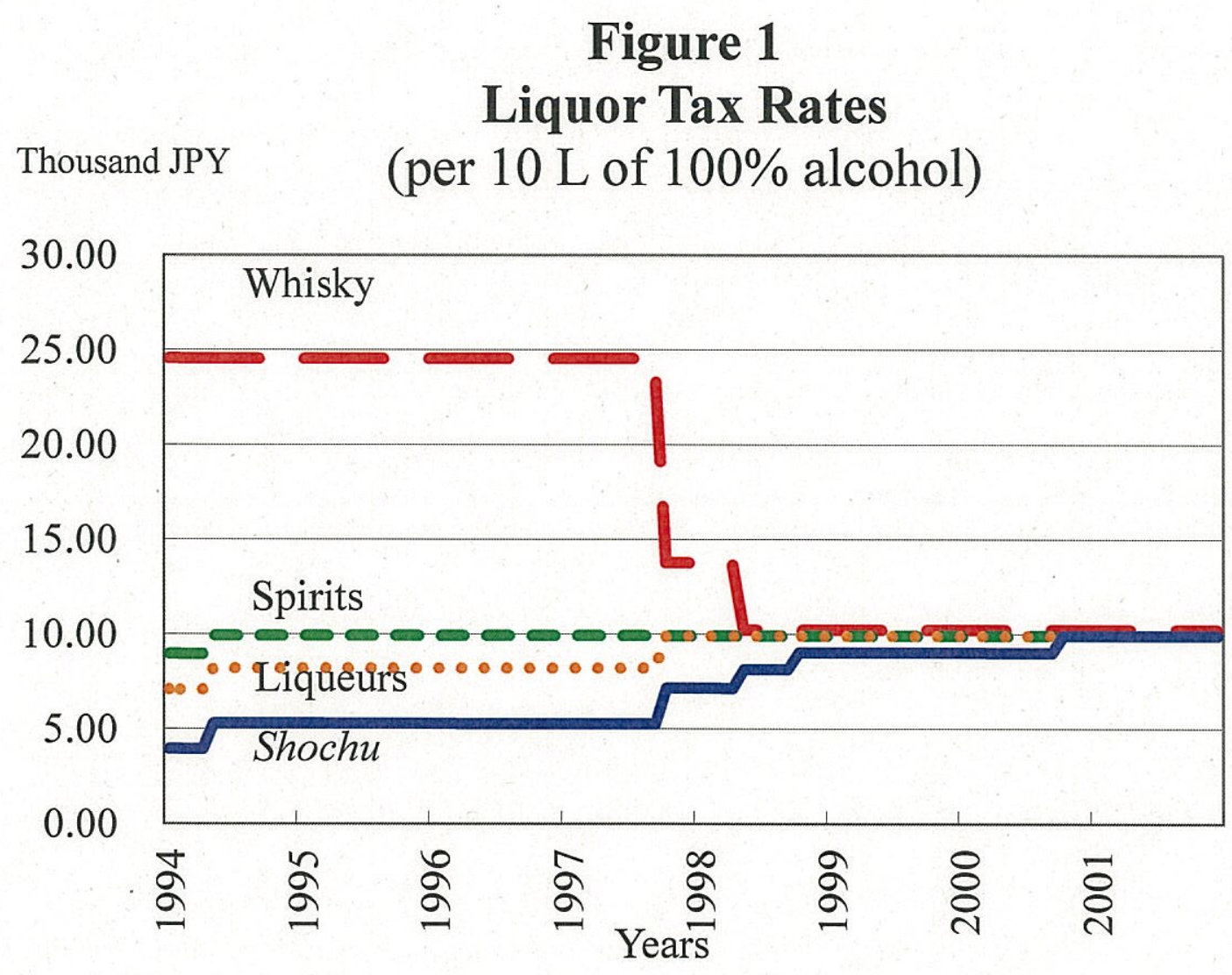


Figure 2

\section{Prices and Quantities}
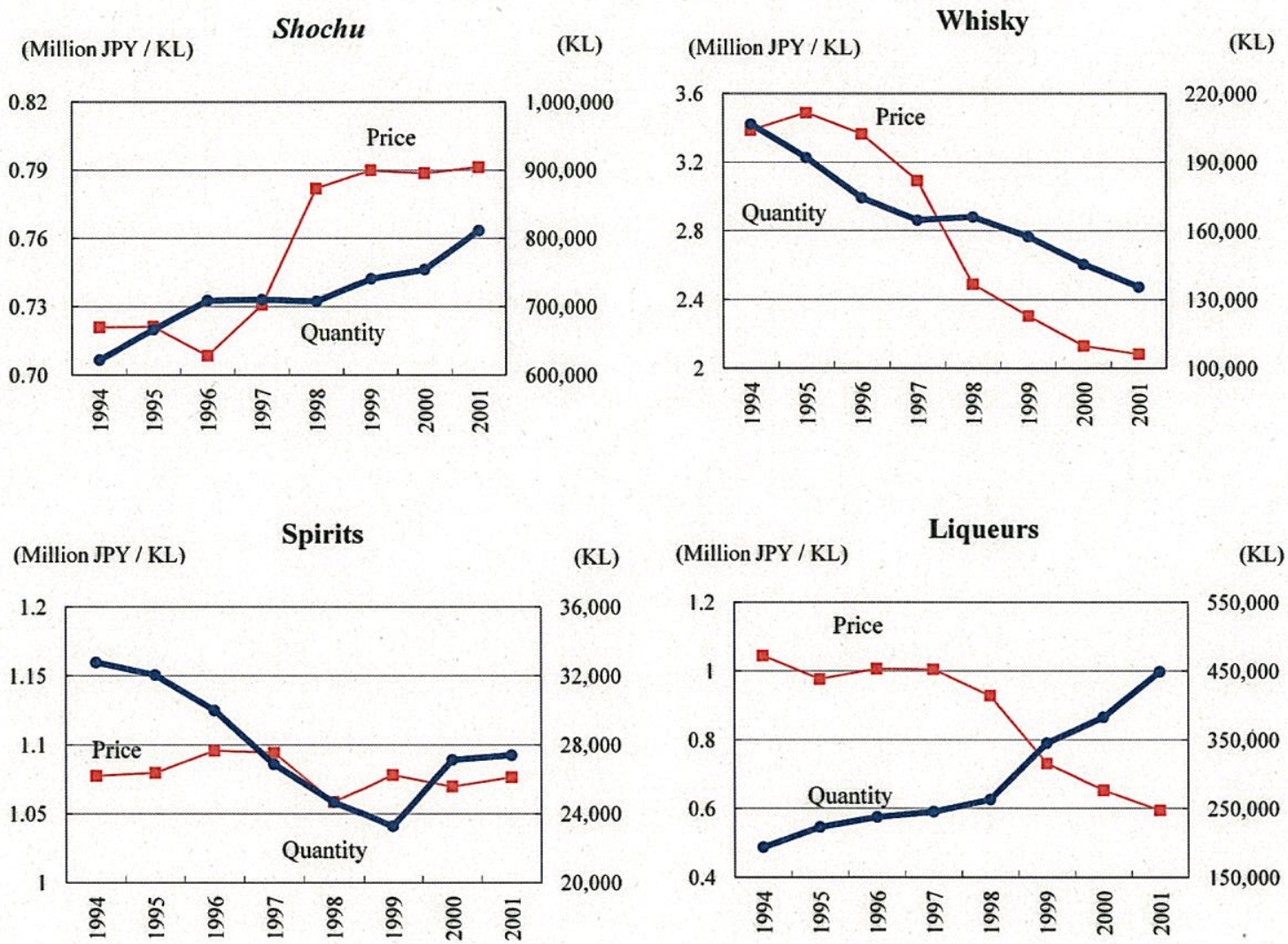

Note: Each panel shows the sum of quantities and the sales-weighted average of prices by year over all markets. 
Figure 3

Optimal and Actual Tax Rates

(per $10 \mathrm{~L}$ of $100 \%$ alcohol)

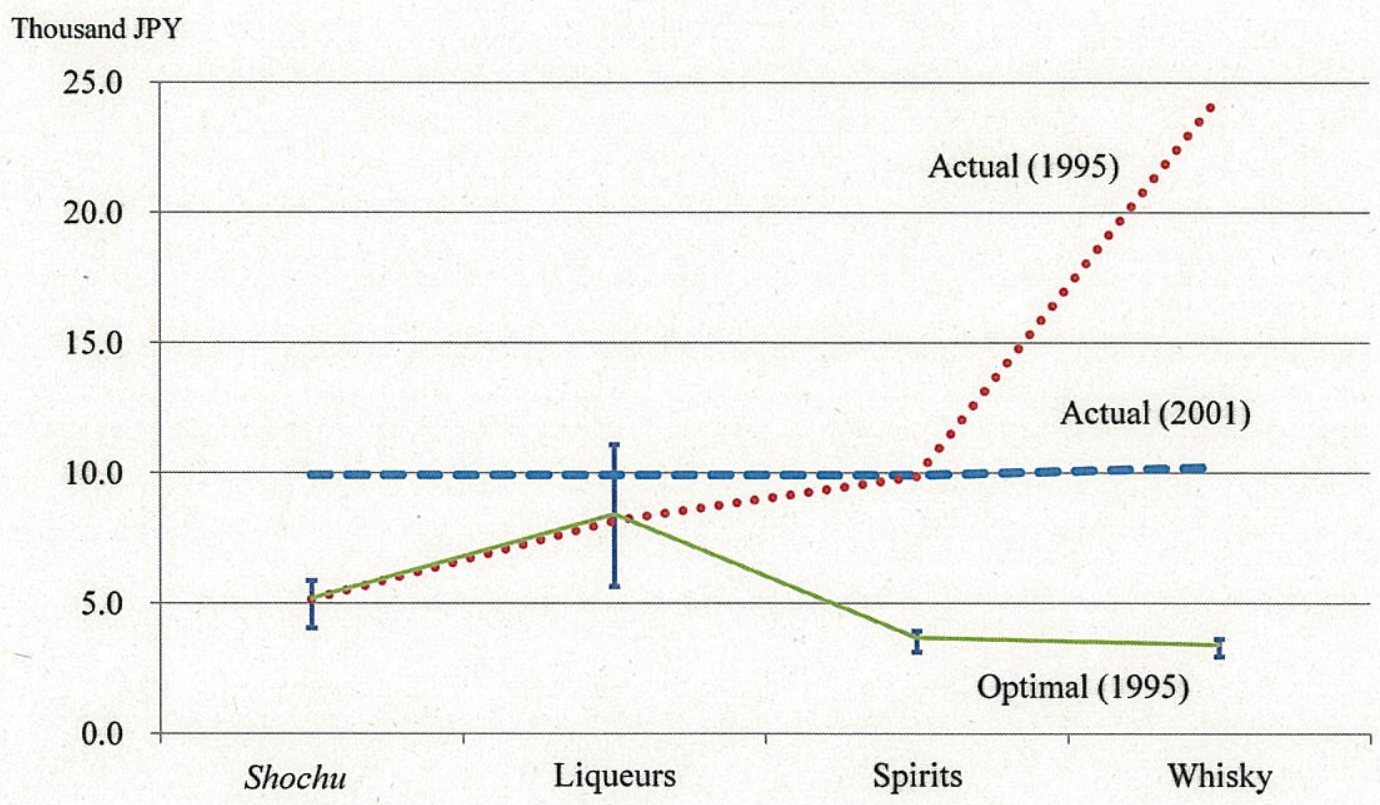

Note: Vertical lines represent $99 \%$ confidence intervals of the optimal tax rates. 


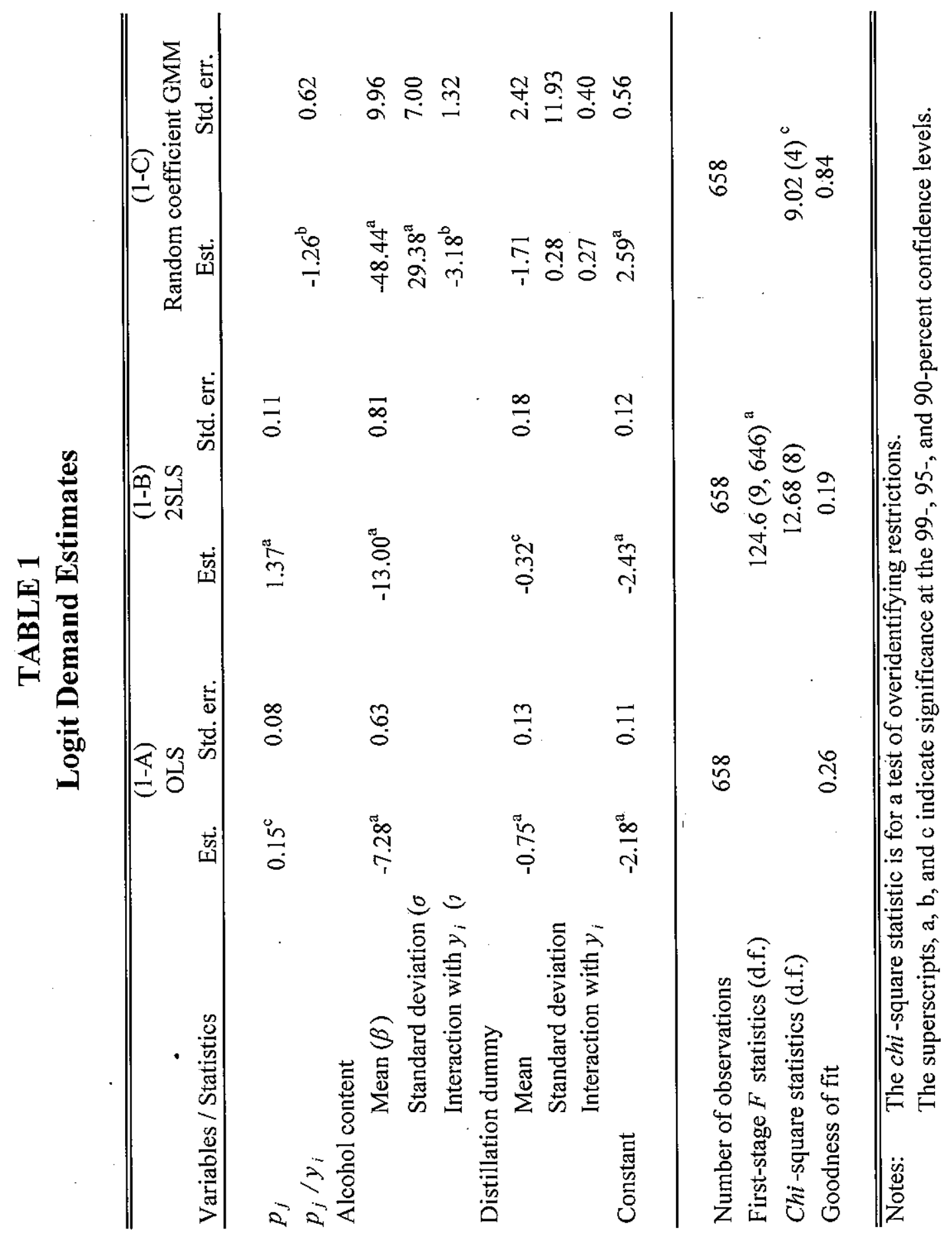




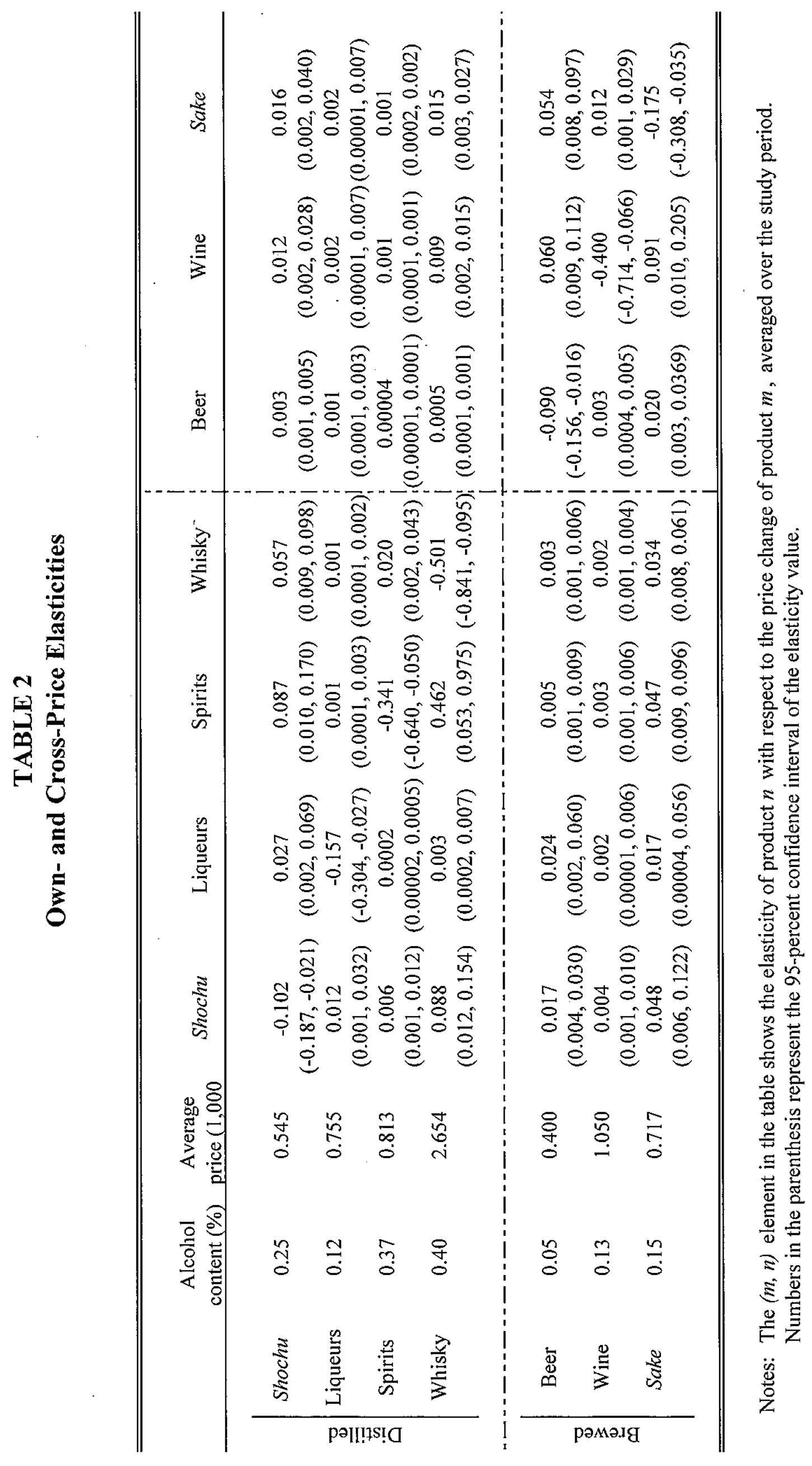




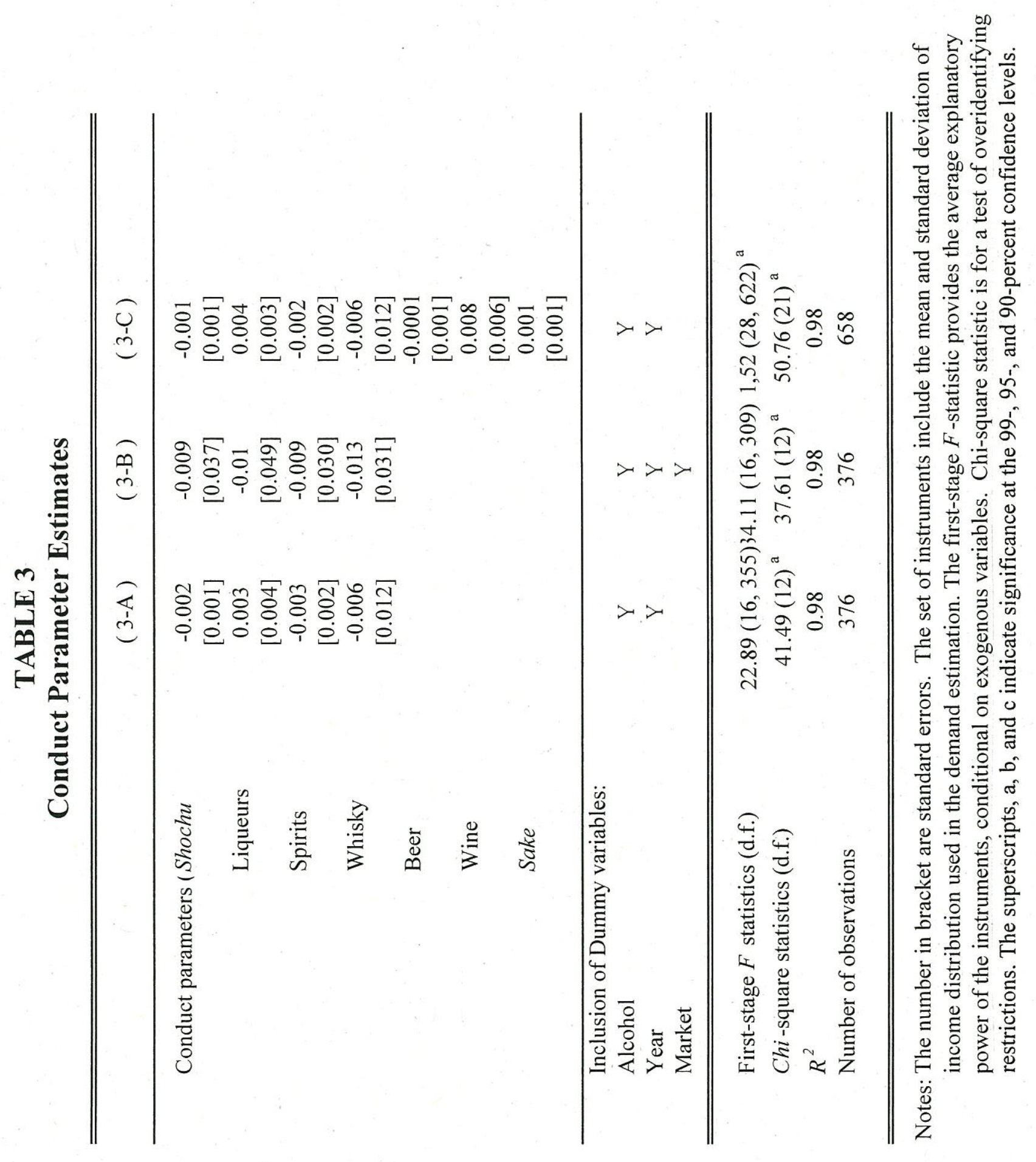




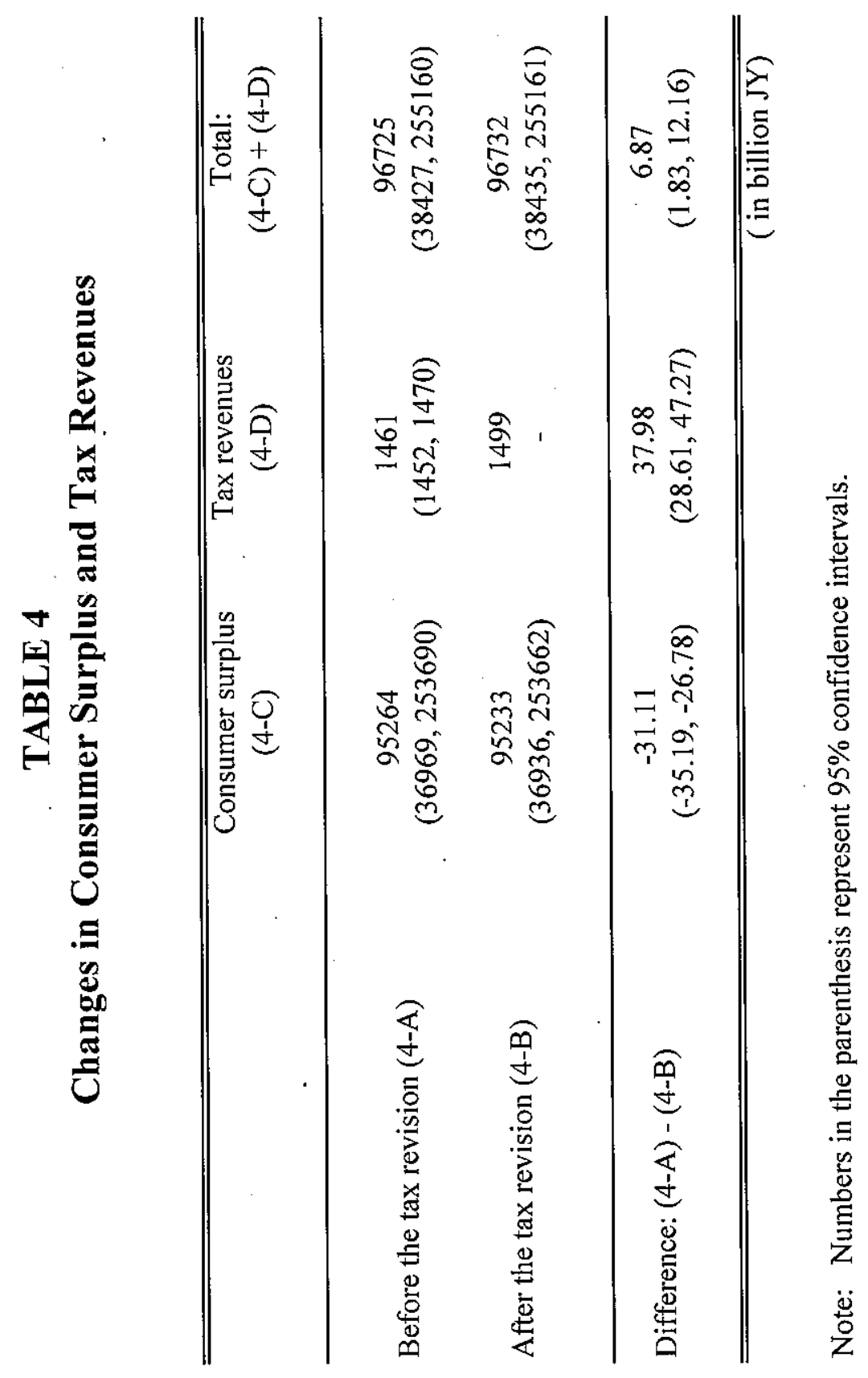

